\title{
Editorial
}

\section{Forest Governance, Decentralization and REDD+ in Latin America}

\section{Elena Petkova $^{1, *}$, Anne Larson ${ }^{2}$, Pablo Pacheco ${ }^{1}$}

1 Center for International Forestry Research, Jalan CIFOR, Situ Gede, Bogor 16000, Indonesia; E-Mail: p.pacheco@cgiar.org

2 Center for International Forestry Research, Managua, Nicaragua; E-Mail: a.larson@cgiar.org

* Author to whom correspondence should be addressed; E-Mail: e.petkova@cgiar.org; Tel.: +359-2-855-9722.

Received: 15 November 2010 / Accepted: 10 December 2010 / Published: 16 December 2010

Forests and their governance have received increased attention in recent years. One factor that has stimulated this renewed interest is the appreciation of deforestation as a significant contributor to greenhouse gas emissions. The emerging REDD+ mechanism (reducing emissions from deforestation and forest degradation) under the UN Framework Convention on Climate Change (UNFCCC) is being designed with the goal of using financial incentives to enhance the role of forests in curbing climate change.

As defined by the UNFCCC and its Bali roadmap, REDD refers to "Policy approaches and positive incentives on issues relating to reducing emissions from deforestation and forest degradation in developing countries; and the role of conservation, sustainable management of forests and enhancement of forest carbon stocks in developing countries” [1]. The plus sign, added in 2009, indicates broad agreement that enhancing carbon stocks is to be included in REDD mechanisms.

Forests play an important role in the global carbon budget, both as carbon sinks and sources. They preserve soil fertility, harbor clean water, maintain ecological balance and preserve the majority of terrestrial biodiversity. They directly support the livelihoods of more than 1.4 billion of the world's poor [2]. To capture these values and preserve them, REDD+ is expected to deliver "co-benefits" such as biodiversity conservation and poverty alleviation.

Despite faltering negotiations at the Conferences of the Parties to the UNFCCC, agreements on REDD+ are going forward, particularly through the Interim REDD+ Partnership, a group of more than 60 donor and developing countries. These agreements bring a promise for-and pledges of - financial flows to developing countries, rich in tropical forests. This funding offers an opportunity to alter 
current development paths that rely on the extraction, depletion or replacement of forest assets, often at the expense of local rights and livelihoods. Whether this shift in development occurs, however, will hinge on difficult and sometimes painful governance reforms that reach far beyond the forests sector, to involve macroeconomic and policies in other sectors, such as agriculture, finance and trade.

After the initial enthusiasm for the potential of REDD+, however, concerns over the effectiveness of this global effort have grown. For example, Ostrom [3] argues that initiatives to reduce the risks associated with the emission of greenhouse gases should encourage polycentric approaches likely to achieve benefits at multiple scales and for disparate actors. Others are concerned with REDD+ impacts on indigenous peoples and communities, the ability of governments to adequately report emissions reductions or to control possible corruption. After all, REDD+ is more than just funding for developing countries and is likely to evolve into a market-based carbon trading system, an option that involves higher stakes and is far more controversial [4].

Policy makers have also begun to realize just how much REDD+ success will depend on changes in forest governance at multiple levels. Numerous controversial issues arising from the multiple demands on forests, their uses and their values has spurred interest in knowing more. As a result, the need for research has spiked.

Forests have often been treated as "idle land" to be converted to "productive" uses, and only in the recent past have forests' multiple functions and values been recognized. Agriculture and ranching, mining and infrastructure developments continue to exert direct and indirect pressures on forested lands, contributing $15 \%$ of global greenhouse emissions [5]. The growth of these sectors is increasingly underpinned by increasing demand from global and domestic markets and policies supporting expansion into forests. These policies almost always benefit relatively small but powerful groups, which have in the past opposed any revision of the status quo and are likely to continue to do so.

The major challenge for research on forest governance today is to analyze how various forest values and uses have been governed, draw lessons regarding the causes of failure and success and identify future options and policy responses for transformational change, if forests and REDD+ are to deliver on their potential.

\section{This issue}

The articles in this issue present different perspectives on forest governance in Latin America with implications for REDD+ design, implementation and outcomes. This issue follows three other, similar studies on forest governance and decentralization also led by the Center for International Forestry Research in collaboration with other organizations and authors. The first, "The Politics of Decentralization: Forests, Power and People”, published in 2005, frames the issues of forest governance and decentralization at a global scale [6]. The second and third, "Lessons from Forest Decentralization: Money, Justice and the Quest for Good Governance in Asia Pacific" [7] and “Governing Africa's Forests in a Globalized World” [8], provide regional perspectives. With the evolution of REDD+ initiatives, the articles in this issue of Forests explore the synergies and relationships among forest governance, decentralization and REDD+ in Latin America.

The articles are organized in four themes: 
Articles under the theme People, forest governance and forests frame the discussion on forest governance and its relation to REDD+ in Latin America. Anne Larson et al. provide an overview of key issues shaping forest governance in Latin America, discuss their relevance for REDD+ implementation and for forest-dependent people and argue that, even though REDD+ is not primarily a governance reform, it will affect or be affected by forest governance. Arnoldo Contreras-Hermosilla examines the deficiencies of the policy and regulatory frameworks affecting forests, the institutional and political barriers to introducing reforms for change in Latin American countries. Fabiano Toni argues that although central authorities may be tempted to centralise control over responsibilities and resources in the context of REDD+, the very nature of Brazilian federalism grants governors sufficient powers to prevent this. Bruno Locatelli et al. discuss opportunities to integrate climate change mitigation and adaptation (M\&A) activities in Latin America so as to maximize local co-benefits and contribute to increased capacity to cope with the risks associated with climate change.

Under the theme on Landscape change, forest management and REDD+ Bastian Lauman et al. use the von Thünen model of land use and the forest transition curve to analyze the potential role of sustainable forest management (SFM) in reducing deforestation and forest degradation; they conclude that other factors such as transaction costs, institutional reform, market competitiveness, culture and social organization should be considered to provide a roadmap to REDD+ and SFM. Pablo Pacheco et al. examine five dominant trends in tropical Latin America which have significant impacts on forested landscape change. These trends involve different groups of rural actors and trade-offs between agricultural development and forest conservation. The authors conclude that no 'one-size-fits-all' approach to REDD+ can deliver both cost effectiveness and equity across diverse landscapes and actors. Robert Nasi et al. assess the economic, governance and technical conditions shaping forest management in tropical Latin America and outcomes on forest condition. The authors propose policy interventions to lower net GHG emissions in logged-over or otherwise degraded forests.

Two articles under the Forest finance and finance for REDD+ theme discuss what has worked and what REDD+ can learn from existing forest finance schemes and standards. "Financing sustainable small-scale forestry" by Marco Boscolo et al. identifies 12 key lessons for REDD+ from past experience with community forestry and SFM financing and concludes that the problem is not the availability of money but access to it by small-scale operators. Maria Tomaselli et al. argue that small and medium forest enterprises (SFMEs) can contribute to carbon emmissions reductions more effectively if REDD+ readiness efforts promote an adequate Business Environment, Business Development Services and better access to Financial Services for them. Eduard Merger et al. compare 10 voluntary certification standards against a set of 6 criteria for their applicability to REDD+ projects and policies. They conclude that voluntary certification provides practical experiences that should be fed into the design of an international regime for REDD+ compliance.

Rights, livelihoods and forests are critical issues for both governance and REDD+ design and implementation. Many of these issues go beyond REDD+ schemes but will influence their expected impacts on indigenous peoples and other communities dependent on forests. In "Rights to forests and carbon” Esteve Corbera et al. examine different forest tenure regimes in Costa Rica, Brazil and Mexicoand discuss how each of them is likely to shape benefit-sharing, the allocation of carbon rights and the distribution of liabilities under REDD+. The authors argue that rights, benefits and liabilities 
are closely linked and addressing only tenure insecurities and conflicts, to ensure REDD+ legitimacy and equity, is insufficient. Chris Van Dam discusses the importance of indigenous territories in Latin America for REDD+ implementation. The author concludes that indigenous territories constitute a new spatial reality that is quantitatively and qualitatively different from the community scale of the past and hold a huge potential for REDD+. Pablo Reed examines the case of Ecuador and the reasons for indigenous opposition to REDD+. He concludes that one of the most critical challenges to REDD+ will be the introduction of a legal, financial, and institutional framework that a diverse and influential indigenous community might be willing to accept. Peter Cronkleton et al. examine community forest management (CFM) in Bolivia, Brazil and Mexico and the role of multiscale governance institutions for REDD+. They argue that REDD+ initiatives will depend on rural people to manage forest resources and should build on the positive experiences of CFM.

In summary, this issue discusses a wide range of topics at the intersection between REDD+ and governance in Latin America, with implications for policy reform and forest resource use, people's rights and livelihoods, and distribution of benefits from forest goods and services. We do not claim that they answer all questions that have emerged on governance and REDD+, but they expand our knowledge and provide an important, regional perspective.

\section{References}

1. Report of the Conference of the Parties on Its Thirteenth Session, Held in Bali from 3 to 15 December. Addendum Part Two: Action Taken By the Conference of the Parties at Its Thirteenth Session. Decision 2/CP.13 Reducing Emissions from Deforestation in Developing Countries: Approaches to Stimulate Action; United Nations Frame Convention on Climate Change: New York, NY, USA, 2007. Available online: http://unfccc.int/resource/docs/2007/cop13/eng/06a01.pdf (accessed on 10 November 2010).

2. Macqueen, D. Review of Funds Which Aim To Protect Tropical Forests; International Institute for Environment and Development: London, UK, 2010.

3. Ostrom, E. Polycentric systems for coping with collective action and global environmental change. Global Environ. Change 2010, 20, 550-557.

4. Durban Group. No REDD! NO REDD Plus! Global Sign-On Campaign against Schemes for Reducing Emissions from Deforestation and Forest Degradation, 13 April 2010. Available online: http://www.durbanclimatejustice.org (accessed on 6 November 2010).

5. $\quad$ van der Werf, G.R.; Morton, D.C.; DeFries, R.S.; Olivier, J.G.J.; Kasibhatla, P.S.; Jackson, R.B.; Collatz, G.J.; Randerson, J.T. $\mathrm{CO}_{2}$ emissions from forest loss. Nat. Geosci. 2009, 2, 737-738.

6. Colfer, C.; Capistrano, D. The Politics of Decentralization: Forests, Power and People; Earthscan: London, UK, 2005.

7. Colfer, C.; Dahal, G.; Capistrano, D. Lessons from Forest Decentralization: Money, Justice and the Quest for Good Governance in Asia-Pacific; Earthscan: London, UK, 2008. 
8. German, L.; Karsenty, A.; Tiani, A. Governing Africa's Forests in a Globalized World; Earthscan: London, UK, 2010.

(C) 2010 by the authors; licensee MDPI, Basel, Switzerland. This article is an open access article distributed under the terms and conditions of the Creative Commons Attribution license (http://creativecommons.org/licenses/by/3.0/). 